\title{
Analysis of retractions puts spotlight on academia
}

About half of the medical papers retracted over the past few decades were pulled because of misconduct rather than an innocent mistake, according to two new studies. And that fraction is on the increase. Yet although drug companies are often portrayed by the popular press as the source of all evil in biomedical publishing, just $4 \%$ of retractions due to misconduct had declared pharmaceutical sponsorship.

"We absolutely should not let up on our scrutiny of industry," says Karen Woolley, a co-author of one of the new studies and chief executive officer of the professional medical writing company ProScribe, based in Queensland, Australia. "But why are we always pointing our finger over there? There's an elephant in the room, and that's the nonfinancial conflicts of interest in academia."

Woolley and Liz Wager, presenter of the second related study at the Sixth International Congress of Peer Review and Biomedical Publication in Vancouver, British Columbia, noted that there are huge pressures in academia to get promotions, funding, grants and status, and this should not be forgotten against the backdrop of increased scrutiny of industry-funded research. "Academic data doesn't get scrutinized at all," says Wager, who is managing director of the Sideview consultancy in Princes Risborough, England and chair of the Committee on Publication Ethics (COPE), a publishing industry forum.

But journal editors remain particularly concerned about undisclosed conflicts of interest in pharmaceutical-sponsored studies. "That's the larger problem," says Ginny Barbour, chief editor of the PLoS Medicne, a journal of the Public Library of Science in Cambridge, UK. Academia does have huge pressures, she agrees, but she notes that industry takes advantage of this fact to spread its own messages.

Under the auspices of COPE, Wager dug through PubMed files to see how many papers had been retracted between 1988 and 2008. She found 529, and, in a close study of a randomly selected set of 312 , she judged that only $28 \%$ were due to "honest error". Among the rest, some of the largest chunks were due to authors found publishing the same results more than once (18\%), plagiarism (15\%), fabrication (5\%) and falsification (4\%) of data. Taking into account an additional $1 \%$ in the 'other misconduct' category, the unethical reasons stacked up to $43 \%$.

Woolley's independent study comes to roughly the same conclusion. She found 463 retractions in English-language papers from 1978 to 2008 that looked specifically at human health. The percentage of these retractions due to misconduct rose from some $40 \%$ in the late 1980 s to $60 \%$ the 2000s. That's probably because editors have become more aware of misconduct, she says, rather than a real increase in misbehavior. The rise corresponds to the establishment of the US Office of Scientific Integrity in 1989 (which became the Office of Research Integrity in 1992), along with fresh guidelines on ethical publication standards from groups such as the International Committee of
Medical Journal Editors, she adds.

Many journals take extra care in reviewing papers with industry ties. In 2005, the Journal of the American Medical Association (JAMA) instigated a rule that pharmaceutical-sponsored papers need to have an independent statistical review to be published.

It is unknown how many of the retracted papers had undisclosed connections with the pharmaceutical industry. Josef Wislar, a research analyst for JAMA in Chicago, told the congress that he found evidence of 'ghostwriting' - uncredited authors - in $7.8 \%$ of papers he studied. The fraction of medical papers that are retracted is much smaller than that (less than $0.1 \%$ ) and could, in principle, all have undisclosed industry backing. But Wager points out that more than half of the retracted papers in her study related to basic biomedical research, which isn't usually sponsored by the pharmaceutical industry, rather than to clinical trials.

Both Wager and Woolley estimate they personally earn about three-fourths of their income by working for pharmaceutical companies. Others without such ties agree that a stronger spotlight should be shone on academic mishandling of data. "It would be good if we could pay more attention to academia, but I don't know how we're going to do it," says Michael Callaham, editor of the Annals of Emergency Medicine in San Francisco. "These conflicts are more subtle and hard to root out. At least with a drug company someone has written a check."

Nicola Jones, Vancouver, Canada with spin," says Altman.

Some spin might be a sign of industry-sponsored work attempting to favor a company's drug. Other cases might be from academics trying to make a paper seem 'stronger', to help it get published. Such pressures are well known and are, at times, understandable, says Altman. But, he adds, "I can see why someone would rob a bank - that doesn't mean I think it's right."

Meanwhile, Eileen Gambrill, a professor at the University of CaliforniaBerkeley who studies professional decision making, is developing a propaganda index to help researchers grow more aware of how the framing and

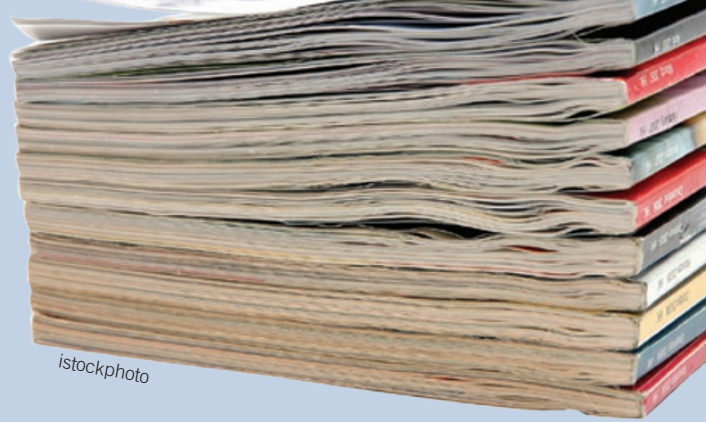

presentation of work affects its meaning. She reckons that having a clearly defined checklist of key words and phrases frequently involved with propaganda can help editors and reviewers to keep it in check. Gambrill, who described the approach at the Vancouver meeting, intends to publish her index in the coming months.

"It's a fascinating idea," says Tom Perry, a clinical pharmacologist at the University of British Columbia, Vancouver and a former elected official in his province of British Columbia.

Working in politics, he says, he became well aware of the power of spin.

The important thing in combating spin, says Altman, is to make editors and authors think about the issue. "Awareness is the first step."

Nicola Jones, Vancouver, Canada 